\title{
Da formação inicial ao ingresso na carreira docente: um diálogo luso-brasileiro ${ }^{1}$
}

Helena Felício²

\section{Resumo}

Este trabalho analisa as representações que os professores, egressos do curso de formação de professores de uma universidade pública brasileira e uma universidade portuguesa, fazem do seu processo de formação inicial, considerando a sua experiência profissional. As informações foram recolhidas por meio de um questionário disponibilizado on-line. Em ambos os contextos os professores reconhecem as positividades e as limitações dos cursos de formação inicial, enfatizando o papel da prática pedagógica e do estágio supervisionado como facilitador deste processo. Os resultados apontam para a necessidade de pensar o currículo de formação em rede que considere a articulação entre universidade e escola de educação básica, a fim de que a transição de estudante à profissional seja menos impactante.

Palavras-chave: Egressos; Formação de Professores; Professores Iniciantes.

\section{From initial training to joining teaching career: a luso-brazilian dialogue}

\section{Resumen}

This work present a reflection over the representations that teachers, alumni of the teacher-training course of a Brazilian public university and a Portuguese university, make of their initial training process, considering their professional experience. The information was collected through a survey-type questionnaire, available online. In both contexts teachers recognize the pros and limitations of initial training courses, emphasizing the role of pedagogical practice and supervised internship as a facilitator of this process. The results point to the need of thinking, on the one hand, of the network training-curriculum that considers the articulation between university and basic education school, so that the transition from student to professional ought to be less impactful. Keywords: Alumni; Teacher-Training; Teacher Beginners.

\section{Introdução}

Fruto de uma parceria de trabalho estabelecida entre professores de uma universidade pública brasileira e uma universidade portuguesa que culminou no desenvolvimento de um conjunto de atividades didáticas, pedagógicas e científicas no âmbito da formação inicial de professores e da inserção destes no contexto de atividade profissional, este trabalho objetiva analisar as representações que os professores, egressos do curso de formação de professores das universidades envolvidas, fazem do seu processo de formação inicial, considerando a sua

\footnotetext{
${ }^{1}$ Pesquisa financiada pelo Conselho Nacional de Desenvolvimento Científico e Tecnológico (CNPq).

2 Universidade Federal de Alfenas (UNIFAL-MG), Alfenas - MG, helena.felicio@unifal-mg.edu.br
} 
experiência profissional.

A entrada na carreira docente, é o tempo que "os professores precisam realizar a transição de estudantes a docentes. É uma etapa de tensões e aprendizagens intensivas em contextos geralmente desconhecidos" (GARCIA, 1999, p.105). Tensões diante da realidade desafiadora que se apresenta, para a qual é preciso conservar um equilíbrio pessoal a fim de que, aos poucos vá superando a insegurança e a falta de confiança na sua própria forma de estar na profissão, agora como profissional, não mais como estudante.

De igual modo, essa entrada na carreira docente, identificada, também, com o período de indução profissional (FLORES, 2000), caracteriza-se pela integração do professor recemformado ao contexto profissional, marcada pelo processo de conhecimento da realidade organizacional da escola; de socialização com os seus pares; de gerência de uma turma de estudantes; de desenvolvimento da ação pedagógica, mediada por um currículo que oscila entre ser centralizado e flexível, a depender do contexto institucional.

Segundo Flores (2000), diferentemente de outras profissões, em que o processo de ingresso na profissão acontece gradativamente, com uma progressão linear em relação à complexidade de tarefas, a entrada no ensino se dá de forma repentina e abrupta. "De um dia para o outro, o professor principiante tem de assumir as mesmas responsabilidades que um professor com experiência, encontrando-se, muitas vezes, isolado e com pouco apoio" (FLORES, 2000, p.45), até mesmo em função da diversificada e complexa dinâmica do cotidiano escolar. É comum verificarmos turmas de estudantes que apresentam maiores desafios, o que exigiria um profissional mais experiente, sendo atribuídas aos professores recém-formados, com a experiência da prática pedagógica desenvolvida somente durante o estágio curricular, no período da formação inicial.

Esta é uma peculiaridade da entrada na docência que se torna, extremamente desafiadora para os jovens professores que precisam, muitas vezes, desenvolver estratégias para sua sobrevivência na profissão (HUBERMAN, 2013), superando esses desafios iniciais vivenciados quase sempre de maneira individual e solitária.

Não temos dúvida da relevância dos primeiros anos de docência para a formulação de um referencial que sustente, tanto o desempenho, quanto a construção de um perfil profissional que seja capaz de, gradativamente, dar respostas assertivas aos desafios que o contexto da sala 
de aula apresenta ao jovem professor. Sem dúvida é uma etapa de crescimento e de maturidade ao longo da qual "torna-se professor" e "aprende-se a ensinar".

Neste processo de "tornar-se professor" é preciso reconhecer as dimensões da formação inicial, tendo a consciência de que ela não dá conta, por si só, de abarcar toda a complexidade do contexto profissional e, de igual modo, reconhecer que o processo de aprendizagem deste ofício se torna mais aprofundado e diversificado a partir da experiência profissional no referido contexto. Ou seja, "é no exercício da docência que se aprende, em parte, a ser professor" (PENNA, 2014). É neste processo que se aprende a dominar progressivamente os saberes que são necessários à realização deste ofício.

No processo de entrada na carreira docente, o contato com o contexto de atividade profissional evidencia aos jovens professores que outros saberes são necessários. Saberes estes, que englobam também habilidades, competências, atitudes relativas à diferentes esferas do seu trabalho, o que nem sempre, segundo Tardif e Raymond (2000), correspondem aos conhecimentos construídos no período de formação inicial. O que não significa, desconsiderar a formação inicial, mas entendê-la como ponto de partida de um processo de construção que passa a ser contínuo.

Segundo os autores, o ingresso na profissão permite um confronto entre a formação inicial e a realidade do contexto educativo, no sentido de que é necessário desmistificar a visão idealista e linear da profissão docente, do cotidiano escolar e do processo de ensino e de aprendizagem, para reajustar suas expectativas e compreender a entrada na profissão como um processo singular da própria construção da docência.

\section{Percurso metodológico}

Este estudo tem como procedimento a análise exploratória de um conjunto de dados quanti-qualitativos fornecidos por 78 (100\%) professores egressos do curso de Pedagogia da universidade brasileira (UB), e 87 (100\%) dos cursos de formação de professores para Educação Básica da universidade portuguesa (UP), que concluíram a formação inicial entre 2010 e 2017, e que, voluntariamente, aceitaram colaborar com este estudo respondendo a um questionário, do tipo survey, disponibilizado on-line. 
Conforme indicado na introdução, o estudo compreende egressos dessas duas universidades em função do acordo de cooperação técnico-científico-cultural firmado entre as duas instituições, no âmbito das ações de internacionalização nas quais ambas se encontram em processo.

O questionário foi estruturado com questões abertas e fechadas, dividido em três blocos: 1ㅇ) Formação inicial e atividade profissional; 2ㅇ) Representação da formação inicial a partir do desenvolvimento da atividade profissional; 3ㅇ) Aspectos determinantes para a inserção profissional.

A delimitação dos cursos é em função de que eles formam professores para atuarem na Educação Infantil e nos anos iniciais do Ensino Fundamental, no Brasil, e etapas correspondentes em Portugal, considerando que os professores envolvidos no projeto lecionam nestes cursos. De igual modo, o recorte temporal se justifica em função do contexto português ter passado pela adequação da formação para os moldes definidos pela declaração de Bolonha, cuja formação passa a ser bietápica, havia a necessidade de garantir que os egressos, participantes deste estudo, fossem provenientes do mesmo modelo formativo.

Assim, estamos falando de professores com, no máximo, 8 (oito) anos de experiência profissional, portanto, de acordo com o ciclo de vida profissional (HUBERMAN, 2013), trata-se de professores que estão em fase de entrada ou de estabilização na carreira docente.

As informações recolhidas por meio do questionário, indicado anteriormente, garantiram uma análise por meio da tabulação dos mesmos no modo simplificado, utilizando-se para isso o software de criação e edição de planilhas Microsoft Exce ${ }^{\circledast}$ e analisados por meio de Estatística Descritiva com auxílio de tabelas de frequências absolutas e relativas, favorecendo, assim, a sistematização de reflexões pertinentes à relação estabelecida pelos participantes entre a sua atividade profissional e o processo de formação inicial.

\section{Breve caracterização dos participantes}

No Brasil, a atuação profissional docente é permitida a partir da conclusão de um curso de graduação em licenciatura. No caso deste estudo, a Pedagogia é o curso que habilita o profissional trabalhar como docente na Educação Infantil e nos anos iniciais do Ensino 
Fundamental. No contexto português, considerando que a formação é desenvolvida a partir da Declaração de Bolonha (SERRALHEIRO, 2005), num processo bietápico, organizado em um primeiro ciclo, compreendido pela Licenciatura em Educação Básica, e o Mestrado em Ensino que confere a habilitação profissional para docência. Deste modo, conforme a tabela 01, identificamos que 32,2\% ( $f=28$ ) concluiram o Mestrado em Educação Pré-Escolar, 40,2\% ( $f=35$ ) concluiram o Mestrado em Educação Pré-Escolar e Ensino do 1ํ Ciclo do Ensino Básico, e, 27,6\% ( $f=24)$ o Mestrado em Ensino do 10 e 2o Ciclo do Ensino Básico.

Ainda no campo da formação, percebemos que no Brasil a busca por outras modalidades de formação, é mais frequente. Dos concluintes do curso de Pedagogia participantes deste estudo, $65,4 \%$ ( $f=51$ ) indicam estar frequentando ou já ter concluído outros estudos em nível superior e ou pós-graduação. Destes, 44,9\% ( $f=35)$ buscou um curso de pós-graduação latu sensu, em diferentes áreas educacionais com o objetivo de especializa-se em algum aspecto que pudesse contribuir para um melhor desempenho no exercício da atividade profissional, ou mesmo, funcionando aqui como um dispositivo de distinção no currículo acadêmico e profissional. De igual modo, um grupo significativo, $15,4 \%(f=12)$, procurou a pós-graduação strictu sensu, mestrado e doutorado, como forma de ascender na carreira acadêmica, e apenas $4,9 \%(f=3)$ buscaram outro curso de graduação.

Tabela 01: Formação Inicial

\begin{tabular}{|c|c|c|c|c|c|}
\hline \multicolumn{2}{|r|}{ Variáveis } & \multicolumn{2}{|c|}{$\begin{array}{l}\text { Professores } \\
\text { egressos UB }\end{array}$} & \multicolumn{2}{|c|}{$\begin{array}{l}\text { Professores } \\
\text { egressos UP }\end{array}$} \\
\hline & & $f=$ & $\%$ & $f=$ & $\%$ \\
\hline \multirow{5}{*}{$\begin{array}{l}\text { Formação } \\
\text { Superior }\end{array}$} & Pedagogia & 78 & $100 \%$ & $\begin{array}{c}-- \\
-\end{array}$ & --- \\
\hline & Mest. Educação Pré Escolar & --- & --- & 28 & $32,2 \%$ \\
\hline & $\begin{array}{l}\text { Mest. Educação Pré-Escolar e Ensino do 10 } \\
\text { ciclo do Ensino Básico }\end{array}$ & --- & --- & 35 & $40,2 \%$ \\
\hline & Mest. Ensino do 1ㅇ e 2o ciclo do Ensino Básico & --- & --- & 24 & $27,6 \%$ \\
\hline & & 78 & $100 \%$ & 87 & $100 \%$ \\
\hline \multirow{6}{*}{$\begin{array}{l}\text { Outra } \\
\text { Formação }\end{array}$} & Outra graduação & 4 & 4,9 & 1 & 1,1 \\
\hline & Especialização & 35 & 44,9 & 5 & 5,7 \\
\hline & Mestrado & 11 & 14,1 & 6 & 6,9 \\
\hline & Doutorado & 1 & 1,3 & --- & --- \\
\hline & Complementação de formação & --- & --- & 2 & 2,3 \\
\hline & & 51 & $65,4 \%$ & 14 & $16,1 \%$ \\
\hline
\end{tabular}

Fonte: Informações coletadas no questionário 
Na realidade portuguesa, a busca por outro curso de formação não se mostra com a mesma regularidade para aqueles que concluíram os dois ciclos necessários para a formação profissional $(16,1 \% ; f=14)$. Assim, em termos de prosseguimento de estudos, teriam a possibilidade de frequentar um 3. ciclo, o que corresponde ao doutorado, ou ainda frequentar pós-graduações de especialização, de nível de Mestrado Acadêmico (não profissionalizante), cuja valorização é eminentemente curricular, ou ainda outros cursos de graduação.

É importante salientar que, por um lado, esta procura de qualificação institucionalizada que agrega graus diferentes de estudo ao currículo pessoal, nem sempre faz parte de uma política de carreira profissional docente. Frente as demandas, cada vez mais complexas do trabalho, "os professores são compelidos a buscar, então, por seus próprios meios, formas de requalificação que se traduzem em aumento não reconhecido e não remunerado da jornada de trabalho" (GASPARINI; BARRETO; ASSUNÇÃO, 2005), uma vez que a formação continuada, a formação em serviço, nem sempre está integrada à própria carga horária de trabalho. Por outro lado, a busca de qualificação também está atrelada às possibilidades de encontrar outros postos para a atividade profissional que apresentem melhores condições de trabalho e de remuneração, frente à desqualificação profissional que o docente enfrenta na sociedade contemporânea.

Consideramos que esses dados apontam um aspecto relevante para o desenvolvimento profissional, tendo em vista o investimento em formação continuada, uma vez que a formação para a docência é um processo inacabado e deve se prolongar após a formação inicial, pelo tempo em que a profissão é exercida, tendo em vista que "a formação compõe-se de distintos momentos, identificados na literatura como inicial e continuada" (FARIAS et al, 2009, p.67).

Interrogados sobre o exercício de atividade docente, no momento deste estudo, como professor(a) titular de turma, 59\% ( $f=46$ ) dos egressos do curso de Pedagogia (UB) e 52,9\% ( $f=46$ ) dos egressos dos cursos de Formação de Professores (UP) indicaram que trabalham na Educação Infantil e/ou anos iniciais do Ensino Fundamental. No entanto, uma quantidade significativa, $12,9 \%(f=10)$ trabalham em outras modalidades de ensino, como a Educação Não Formal, e outros níveis de ensino, como anos finais do Ensino Fundamental, Ensino Médio e Ensino Superior, sendo necessário considerar que aqueles que estão atuando nesta última modalidade, são legitimados por terem concluído a pós-graduação strictu sensu, que no Brasil, tem também o objetivo de preparar docentes para esse nível de ensino. 
No que diz respeito à jornada de trabalho semanal em escolas, a tabela 02 evidencia que $14,1 \%(f=11)$ dos professores brasileiros trabalham até 20 horas semanais, o que corresponde a um turno de trabalho, $39,8 \%$ ( $f=31$ ) indicam que trabalham entre 21 e 40 horas semanais, o que corresponde a atividade em um turno ou em dois turnos escolares. No entanto, 5,1\% ( $f=4)$ indicam que trabalham mais de 40 horas semanais, o que representa uma carga de trabalho excessiva, considerando todas as atividades que o professor precisa desenvolver fora de sala de aula e que, nem sempre, estão contabilizadas como hora de trabalho efetivo. Isso se dá em função do tipo de jornada de trabalho do professor brasileiro, em geral contabilizada por hora/aula de trabalho efetivo em sala de aula, o que provoca impactos, sobretudo no que diz respeito à qualidade do trabalho realizado, à valorização profissional e às condições de trabalho e de vida deste professor.

No caso português, quanto à Educação Pré-Escolar e ao 1.ํ Ciclo do Ensino Básico, o ensino está organizado em horário integral e a designação do professor (a) se dá para uma determinada escola/horário completo, que corresponde a 25 horas letivas semanais ( 5 por dia). No que se refere ao 2. Ciclo, a designação é atribuída por áreas disciplinares, pelo que pode acontecer a ocupação de necessidades temporárias com horários ditos não completos. Assim, como aponta a tabela $41,4 \%(f=36)$ dos professores indicam trabalhar em horário completo e $11,5 \%(f=10)$ dos professores trabalham em horário incompleto que varia entre 10 e 20 horas de trabalho.

Tabela 02: Jornada de Trabalho

\begin{tabular}{|c|c|c|c|c|c|}
\hline \multicolumn{2}{|r|}{ Variáveis } & \multicolumn{2}{|c|}{$\begin{array}{l}\text { Professores } \\
\text { egressos UB }\end{array}$} & \multicolumn{2}{|c|}{$\begin{array}{l}\text { Professores } \\
\text { egressos UP }\end{array}$} \\
\hline & & $f=$ & $\%$ & $f=$ & $\%$ \\
\hline \multirow{8}{*}{$\begin{array}{l}\text { Jornada de } \\
\text { Trabalho }\end{array}$} & Até 10 horas & 3 & 3,8 & $\begin{array}{c}-- \\
\end{array}$ & $\begin{array}{ll}-- \\
-\end{array}$ \\
\hline & De 11 a 20 horas & 8 & 10,3 & --- & --- \\
\hline & De 21 a 30 horas & 19 & 24,4 & --- & --- \\
\hline & De 31 a 40 horas & 12 & 15,4 & --- & --- \\
\hline & Acimad e 40 horas & 4 & 5,1 & --- & --- \\
\hline & Horário completo & --- & --- & 36 & 41,4 \\
\hline & Horário incompleto & --- & --- & 10 & 11,5 \\
\hline & & 46 & $59 \%$ & 46 & $52,9 \%$ \\
\hline \multirow{5}{*}{$\begin{array}{c}\text { Rede de } \\
\text { Ensino }\end{array}$} & Escola Pública & 35 & 44,8 & 16 & 18,4 \\
\hline & Escola Privada & 6 & 7,7 & 30 & 34,5 \\
\hline & Escola Pública e Privada & 4 & 5,1 & --- & +-- \\
\hline & Público Federal & 1 & 1,3 & --- & --- \\
\hline & & 46 & $59 \%$ & 46 & $52,9 \%$ \\
\hline
\end{tabular}

Fonte: Informações coletadas no questionário 
Em relação à rede de ensino em que esses profissionais trabalham, a mesma tabela indica que 44,8\% ( $f=35$ ) dos respondentes brasileiros trabalham na Rede Pública de Ensino (municipal ou estadual) e $7,7 \%$ ( $f=06$ ) dos professores atuam também nas escolas particulares. Situação contrária percebe-se entre professores portugueses, em que $34,5 \%(f=30)$ trabalham na Rede Privada de Ensino e $18,4 \%$ ( $f=16)$ trabalham no ensino público. Isso também se deve ao crescimento populacional, no caso brasileiro, que exige a oferta de mais vagas nas escolas e consequentemente mais postos de trabalho. E em Portugal, observa-se um congelamento na oferta de novos postos de trabalho e um envelhecimento do quadro de professores que permanecem nesses postos por longos tempos, sem a abertura de novas vagas para os professores recém-formados.

\section{Representação da formação inicial a partir da atividade profissional}

Neste processo, para além da visão global do curso, tendo como referência o exercício da docência, em que os participantes foram convidados a identificarem as positividades e as limitações na formação inicial, bem como os aspectos do curso de formação que foram determinantes para a inserção profissional no mercado de trabalho, privilegiamos um olhar mais aguçado para os elementos formativos que congreguem o Practicum, entendido como “momentos estruturados de prática pedagógica (estágio, aula prática, tirocínio) integrados nos programas de formação de professores" (ZEICHNER, 1992), os quais se apresentam a partir de diferentes configurações no currículo formativo, sob a forma de Prática Pedagógica, enquanto componente curricular obrigatório, e sob a forma de Estágio Curricular Supervisionado.

\section{As positividades e as limitações na formação inicial}

Em termos globais, a construção de significados para as positividades e limitações da formação inicial se deu por intermédio de indicações livres sobre os aspectos que os participantes consideraram que melhor foram trabalhados e aqueles que apresentaram algumas limitações no processo de formação inicial. Considerando que a formação profissional em Portugal se efetiva a partir de dois ciclos de estudo, a saber: Licenciatura e Mestrado Profissional, 


\section{HSE HORIZON TES}

fizemos aqui a distinção entre as indicações apresentadas pelos egressos nos dois níveis.

Tendo em conta o número de indicações e na tentativa de evitar a pulverização delas, optamos por organizá-las nas seguintes categorias: (a) "formação teórico-prático", (b) "dimensões metodológicas do curso" e (c) "competência profissional", conforme tabela abaixo.

Tabela 03: Aspectos trabalhados no curso

\begin{tabular}{|c|c|c|c|c|c|c|c|c|}
\hline \multicolumn{3}{|l|}{ Variáveis } & \multicolumn{2}{|c|}{ UB } & \multicolumn{2}{|c|}{$\begin{array}{c}\text { UP } \\
\text { Licenciatura }\end{array}$} & \multicolumn{2}{|c|}{$\begin{array}{c}\text { UP } \\
\text { Mestrado }\end{array}$} \\
\hline & & & $f=$ & $\%$ & $f=$ & $\%$ & $f=$ & $\%$ \\
\hline \multirow{6}{*}{ 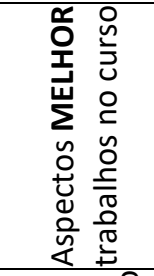 } & \multirow{2}{*}{$\begin{array}{l}\text { Formação } \\
\text { Prático }\end{array}$} & Teoria & 42 & 53,9 & 29 & 33,3 & 11 & 12,6 \\
\hline & & Prática & 6 & 7,7 & 22 & 25,3 & 21 & 24,1 \\
\hline & \multicolumn{2}{|c|}{ Dimensão Metodológica do Curso } & 16 & 20,6 & 17 & 19,4 & 12 & 13,7 \\
\hline & \multicolumn{2}{|c|}{ Competência Profissional } & 8 & 10,2 & 4 & 4,6 & --- & --- \\
\hline & \multicolumn{2}{|l|}{ Não respondeu } & 6 & 7,7 & 15 & 17,2 & 43 & 49,4 \\
\hline & & & 78 & $100 \%$ & 87 & $100 \%$ & 87 & $100 \%$ \\
\hline \multirow{6}{*}{ 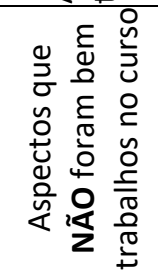 } & \multirow{2}{*}{$\begin{array}{l}\text { Formação } \\
\text { Prático }\end{array}$} & Teoria & 9 & 11,5 & 40 & 45,8 & 13 & 14,9 \\
\hline & & Prática & 36 & 46,1 & 30 & 34,4 & 13 & 14,9 \\
\hline & \multicolumn{2}{|c|}{ Dimensão Metodológica do Curso } & 10 & 12,9 & 6 & 6,9 & 10 & 11,4 \\
\hline & \multicolumn{2}{|l|}{ Competência Profissional } & 9 & 11,6 & 1 & 1,1 & 8 & 9,2 \\
\hline & \multirow{2}{*}{\multicolumn{2}{|c|}{ Não respondeu }} & 14 & 17,9 & 10 & 11,5 & 43 & 49,4 \\
\hline & & & 78 & $100 \%$ & 87 & $100 \%$ & 87 & $100 \%$ \\
\hline
\end{tabular}

\section{Formação teórico-prática}

No que se refere à formação teórico-prática, percebemos que o aprofundamento teórico foi considerado como um ápice no processo de formação nos dois contextos. De fato, percebese que há uma avaliação muito positiva relativa aos fundamentos teóricos em várias áreas do conhecimento, sendo que isso é visto como um suporte de argumentação profissional e de tomada de decisões em coerência com pressupostos das correntes educativas modernas. Os egressos também indicam que algumas disciplinas específicas, relacionadas com a Didática, as Metodologias Específicas para o trabalho com as diferentes áreas de conhecimento, a Educação Infantil, foram bem trabalhadas durante o curso. De igual forma, aqueles componentes que remetem à Prática Profissional, como o Estágio Supervisionado, as Práticas Pedagógicas e as atividades que proporcionaram uma relação mais estreita com o contexto escolar, foram apontados como significativos no processo de formação.

Periódico Horizontes - USF - Itatiba, SP - Brasil - e021045 
Em contrapartida, de forma contraditória, também foram indicadas limitações em relação aos mesmos aspectos. Isso acontece com disciplinas específicas, sobretudo aquelas consideradas, pelos egressos, como fundamentais na atividade docente, no contato direto com os estudantes, pelo que são referenciadas disciplinas que trabalham com o conhecimento de áreas específicas, nomeadamente, a Matemática, a Alfabetização, as Ciências Naturais, a Geografia, as Necessidades Especiais Educativas, a Avaliação, entre outras.

De igual maneira, foram indicadas limitações referentes à Prática Profissional, aos diferentes momentos da Prática Pedagógica ao longo da formação. Nos dois contextos, os professores apontam para a necessidade de os cursos cuidarem com mais afinco da dimensão prática do curso, uma vez que é essa dimensão que os coloca em contato com o futuro campo de atividade profissional. Assim, é necessário possibilitar mais e diversificadas vivências no cotidiano escolar, o que inclui o conhecimento e o estudo de diferentes realidades educativas; bem como a necessidade de intensificar e aprofundar o acompanhamento dos Estágios, de modo a que se estabeleçam patamares elevados de confiança e segurança aos futuros professores em formação.

Esse contato com a realidade e o seu devido acompanhamento deve ser considerado de forma gradativa e precoce na formação, desde os primeiros anos de curso, mantendo-se presente ao longo do mesmo, culminando em processos de Estágios intensivos e devidamente supervisionados, tanto pelos contextos escolares como pelos acadêmicos, a partir de referenciais de competências e atividades que devem ser desenvolvidas, de processos de supervisão comuns, discutidos e compartilhados, em diferentes momentos e instâncias, por todos os intervenientes do processo.

Assim, torna-se evidente nas manifestações dos egressos a importância da Prática Profissional na formação inicial, entendida como processo que ajuda o futuro profissional a construir respostas pertinentes e assertivas, devidamente fundamentadas e contextualizadas, às exigências da atividade profissional nos mais diversos contextos educativos.

Ao considerar as positividades e limitações, os egressos apontam, conforme Tardif (2002), que teoria e prática não devem ser interpretadas como polos distintos ou dicotômicos nos currículos de formação de professores. Pelo contrário, devem constituir-se como dimensões de um mesmo processo formativo, onde a teoria é formulada a partir da realidade educacional e a 
prática, por sua vez, é alimentada pela teoria, exigindo, assim, um professor que seja capaz de responder às necessidades apresentadas pela realidade educacional.

Nesse sentido, observa-se que a dificuldade em superar uma certa fragmentação do currículo de formação se evidencia na organização e nas práticas institucionais. Disso depreendese também que, para superar essa fragmentação, cabe ao estudante, professor em formação, estabelecer, por si mesmo, as relações que não se efetivam entre as disciplinas do curso. Contudo, para que isso aconteça, entende-se que o currículo de formação deve dar espaço para que os estudantes tenham consciência do mesmo, das suas potencialidades e especificidades, o que requer um processo de análise e meta-reflexão sobre a formação que os futuros professores experienciam, no sentido de lhes ser possível atribuir, de forma progressiva, significados próprios e que estes possam ser revertidos para o conhecimento detalhado acerca da realidade educativa sobre a qual estão/vão intervir.

\section{Dimensões metodológicas do curso}

Nos últimos tempos, com muita frequência, a educação formal tem sido questionada quanto ao uso arraigado das metodologias convencionais de ensino e de aprendizagem, baseado na transmissão oral dos conteúdos. A inovação pedagógica e curricular tem sido o desafio a ser construído pelos professores em sua ação docente, sobretudo pelo uso de tecnologias de informação.

Para Cunha (2008), inovação não se restringe a inclusão de novidades, até mesmo a tecnológica, mas, precisa ser, sobretudo, uma ruptura paradigmática do que vem a ser a construção do conhecimento da sociedade moderna, de modo que uma nova forma de entender tal construção se reverbere nos procedimentos metodológicos em um determinado curso de formação.

Assim, 20,6\% ( $f=16)$ dos egressos da UB, 19,4\% ( $f=17)$ dos egressos da Licenciatura e $13,7 \%(f=12)$ dos egressos dos mestrados da UP, conforme a tabela 03 , indicam como positividades algumas dimensões metodológicas do curso, como o uso de tecnologias; as propostas mais interativas no trabalho com os conteúdos formativos; a relação de ensino e de aprendizagem estabelecida com os professores, marcada pelo acompanhamento nas atividades; 
a relação entre a teoria e prática; a formação científica evidenciada nas propostas investigativas ao longo do curso e/ou experiências específicas em Iniciação à Pesquisa; e a dinamicidade do curso que oferecem uma variedade de possibilidades formativas.

Dialeticamente, para essas dimensões metodológicas também foram assinaladas algumas limitações. Dentre elas destacamos: a falta de sistematização no feedback das atividades; o processo de avaliação pouco transparente; algumas didáticas utilizadas em sala de aula que não contribuíram para o processo de aprendizagem, não sendo estabelecidos nexos ou vínculos significativos entre essa didática e o trabalho docente; uma carga de trabalho excessiva para além das aulas, em detrimento de dinâmicas formativas mais participativas e reflexivas, onde fosse possível fazer a integração das dimensões teóricas e do trabalho prático nas próprias aulas; teorias e conteúdos trabalhados sem relação evidente com o contexto de atividade profissional, sendo que noutros casos a construção dessas relações se faz em tempos e modos muito diferenciados, pelo que não ajudam a uma melhor integração e compreensão desses conhecimentos para o desempenho profissional.

Segundo Roldão (2007), ensinar se constitui em um processo de fazer aprender alguma coisa a alguém. Deste modo, há de se considerar que a dimensão metodológica do curso e dos professores formadores deve ser intencional e orientada, e ter especial relevância, rompendo, por assim dizer, com a forma tradicional de ensinar e aprender, para construir estratégias de ensino que valorizem a gestão participativa, a reconfiguração dos saberes, a reorganização da relação teoria/prática, a perspectiva orgânica da avaliação, a mediação e o protagonismo discente (CUNHA, 2008), tão necessário no momento da inserção profissional.

Uma alternativa que consideramos pertinente para responder às questões metodológicas dos currículos de formação relaciona-se com a possibilidade de, como princípio base dessa formação, assumir o desenvolvimento curricular a partir de estratégias que possam promover a melhoria da atividade profissional docente e da escola. Situação que se torna próxima dos processos metodológicos da investigação-ação colaborativa, onde se conjuga a integração de contextos de formação e de intervenientes, cujos propósitos passam, de forma dialética, pela melhoria das práticas formativas e das práticas educativas (ALONSO, 1998).

Nesse sentido, defendemos a importância de pensar a formação de professores através da elaboração de um projeto integrado, em que a explicitação dos processos metodológicos 
ganham uma relevância acrescida, tanto ao nível das diferentes áreas do conhecimento, como do próprio projeto ou currículo de formação, abandonando, assim, as concepções de um currículo de formação tipo "plano mosaico", caracterizado pela justaposição de saberes, para um "currículo como um projeto de formação" (ROLDÃO, 2001).

\section{Competência profissional}

Segundo Roldão (2007), a competência emerge quando, perante uma determinada situação, o sujeito é capaz de mobilizar adequadamente diversos conhecimentos prévios, selecioná-los, integrá-los de forma adequada à situação em questão.

É preciso considerar que tais conhecimentos não se restringem, somente, aos aspectos conceituais. Assim, podemos verificar, conforme a tabela 03, que há referências aduzidas pelos egressos no sentido de que o trabalho, mesmo que isolado, com atividades e processos que favorecem o desenvolvimento da autonomia, da ética profissional, da criticidade, da reflexividade e da consciência profissional, foram elementos positivos, trabalhados ao longo dos cursos em uma perspectiva de transversalidade, embora possam encontrar em alguns componentes curriculares espaços e tempos privilegiados para a sua sistematização e aprofundamento. Conhecimentos esses, que podem ser, constantemente, mobilizados para o exercício profissional da docência.

Deste modo, fica evidente que, na formação de professores, os conhecimentos atitudinais, além de serem de extrema relevância para a atuação e o desenvolvimento profissional, não precisam - e nem devem - estar alocados em uma determinada disciplina do curso. Muito pelo contrário, sua presença na transversalidade do currículo incide de forma significativa na formação deste profissional.

Por outro lado, também foram indicados como limitações a pouca ênfase dada à função do "pedagogo"; ao relacionamento com os profissionais mais experientes, no sentido de uma socialização profissional crítica; aos processos de aprendizagem de metodologias de investigação, congruentes com a necessidade de produção de conhecimento, enquanto estratégia formativa e de intervenção pedagógica; assim como ao conhecimento da ética e da deontologia profissional da docência. 
Em relação à função do "pedagogo" (situação específica do Brasil), é preciso considerar que, a partir do momento em que o curso de Pedagogia assume, por força legal, a formação dos professores, fragilizou o entendimento da Pedagogia enquanto campo de conhecimento que se debruça sobre a problemática educativa na sua totalidade (LIBÂNEO, 2007). Nesta situação reforça-se a necessidade de trabalhar na formação inicial procedimentos de metodologia de investigação que capacitem o professor a agir, não só como um agente da intervenção pedagógica, mas também como produtor de conhecimento sobre essa ação ou outras temáticas de interesse educativo, na linha de um profissional investigativo (ALARCÃO, 1996).

No tocante ao relacionamento com os profissionais mais experientes, Nóvoa (2012, p.20) adverte que é "preciso passar a formação de professores para dentro da profissão", o que significa "dar aos professores um maior peso na formação de seus futuros colegas e dos seus pares". É preciso compreender que os professores das Escolas de Educação Básica são, também, formadores, no desenvolvimento da prática pedagógica nos contextos educacionais, no processo daquele que está em formação inicial.

\section{Relevância da prática pedagógica e do estágio curricular supervisionado}

Como indicamos anteriormente, estamos nomeando a Prática Pedagógica e o Estágio Curricular Supervisionado como practicum, que, segundo Formosinho, é o "componente curricular de formação profissional de professores cuja finalidade explícita é iniciar os alunos no mundo da prática docente e desenvolver as competências práticas inerentes a um desempenho docente adequado e responsável" (FORMOSINHO, 2009, p.98).

Trata-se de uma inserção intencional no contexto profissional que deve, acima de tudo, qualificar o processo de formação inicial no sentido de oportunizar, por um lado, a vivência real do exercício da futura profissão, e, por outro lado, a construção de um processo de açãoreflexão-ação mediante a confluência de teoria e prática, que permite um agir docente qualificado e intencional.

Nos contextos analisados, eles se configuram de maneira diferenciada. No curso de Pedagogia da UB, o Practicum é estruturado nas modalidades da Prática Pedagógica, como componente curricular, integrado a diversas unidades curriculares, desenvolvido ao longo do 
curso, podendo assumir diferentes configurações, a depender do professor formador, e no Estágio Curricular Supervisionado, como um componente que deve, obrigatoriamente, ser desenvolvido a partir da segunda metade do curso, ou seja entre o quinto e oitavo períodos, em contextos escolares de Educação Infantil e anos iniciais do Ensino Fundamental.

Já nos cursos de formação de professores da UP, o Practicum é organizado a partir de uma unidade curricular, denominada de Iniciação à Prática Profissional (IPP), desenvolvida nos âmbitos da Licenciatura em Educação Básica e no Mestrado, e a partir da Prática de Ensino Supervisionada (PES), que ocorre somente no último período do Mestrado.

A tabela 04 e 05, nos indica que esta é uma dimensão muito valorizada pelos discentes no processo de formação inicial. Mais de $80 \%$ dos egressos do curso de Pedagogia indicam o Practicum como "Muito Relevante" ou "Relevante" e no caso dos egressos dos cursos da UP, percebe-se um aumento significativo desta percepção para as categorias "Muito Relevantes" e "Relevantes" na medida em que os egressos avançam da Licenciatura para os Mestrados, considerando que nos Mestrados os créditos destinados a esse componente são maiores, intensificados e concentrados em um único momento.

Tabela 04: Percepção da relevância do Practicum para os Egressos do curso de Pedagogia da UB

\begin{tabular}{l|c|c|c|c|c|c|c|c|c|c}
\hline & \multicolumn{2}{|c|}{$\begin{array}{c}\text { Muito } \\
\text { Relevantes }\end{array}$} & \multicolumn{2}{c|}{ Relevantes } & \multicolumn{2}{c|}{$\begin{array}{c}\text { Pouco } \\
\text { Relevantes }\end{array}$} & \multicolumn{2}{c|}{$\begin{array}{c}\text { Nada } \\
\text { Relevantes }\end{array}$} & \multicolumn{3}{c}{ Total } \\
\hline & $\mathrm{f}=$ & $\%$ & $\mathrm{f}=$ & $\%$ & $\mathrm{f}=$ & $\%$ & $\mathrm{f}=$ & $\%$ & $\mathrm{f}=$ & $\%$ \\
\hline $\begin{array}{l}\text { Práticas } \\
\text { Pedagógicas }\end{array}$ & 49 & 62,8 & 26 & 33,3 & 3 & 3,8 & --- & -- & 78 & $100 \%$ \\
\hline $\begin{array}{l}\text { Estágio } \\
\text { Curricular }\end{array}$ & 44 & 56,4 & 25 & 32,1 & 8 & 10,3 & 1 & 1,3 & 78 & $100 \%$ \\
\hline
\end{tabular}

Tabela 05: Percepção da relevância do Practicum para os Egressos dos cursos da UP

\begin{tabular}{l|c|c|c|c|c|c|c|c|c|c}
\hline & \multicolumn{3}{|c|}{$\begin{array}{c}\text { Muito } \\
\text { Relevantes }\end{array}$} & \multicolumn{2}{c|}{ Relevantes } & \multicolumn{2}{c|}{$\begin{array}{c}\text { Pouco } \\
\text { Relevantes }\end{array}$} & \multicolumn{2}{c|}{$\begin{array}{c}\text { Nada } \\
\text { Relevantes }\end{array}$} & \multicolumn{2}{c}{ Total } \\
\hline & $\mathrm{f}=$ & $\%$ & $\mathrm{f}=$ & $\%$ & $\mathrm{f}=$ & $\%$ & $\mathrm{f}=$ & $\%$ & $\mathrm{f}=$ & $\%$ \\
\hline IPP - Licenciatura & 34 & 39,1 & 34 & 39,1 & 15 & 17,2 & 4 & 4,6 & 87 & $100 \%$ \\
\hline IPP - Mestrado & 57 & 65,5 & 22 & 25,3 & 6 & 6,9 & 2 & 2,3 & 87 & $100 \%$ \\
\hline PES - Mestrado & 71 & 81,6 & 13 & 14,9 & 3 & 3,4 & --- & --- & 87 & $100 \%$ \\
\hline
\end{tabular}

Se por um lado, esses dados indicam a relevância do Practicum no processo de formação inicial, no reconhecimento de que essa dimensão formativa, intencionalmente, planejada, 
justificada, realizada, analisada e avaliada, se constitui enquanto processo formativo capaz de contribuir para a "construção dos saberes profissionais e para a imersão dos estudantes, candidatos a professores, nos processos de ensino e aprendizagem, onde esses saberes se constroem e ganham uma dimensão fulcral para a ação do professor" (SILVA; FELíCIO, 2017, p.376). Por outro lado, os egressos que atuam como professores indicam, conforme a tabela 06, que a aproximação com a realidade escolar e o exercício da prática profissional foram os aspectos que mais fizeram falta durante a formação inicial.

Tabela 06: Aspectos que mais fez falta no curso de formação

\begin{tabular}{|c|c|c|c|c|c|}
\hline \multirow{2}{*}{\multicolumn{2}{|c|}{ Variáveis }} & \multicolumn{2}{|c|}{ Egressos UB } & \multicolumn{2}{|c|}{ Egressos UP } \\
\hline & & $f=$ & $\%$ & $f=$ & $\%$ \\
\hline \multirow{9}{*}{ 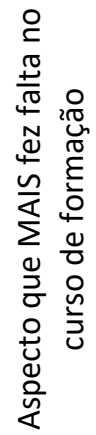 } & Aprofundamento Didático / Metodológico & 06 & 7,7 & 09 & 10,3 \\
\hline & $\begin{array}{l}\text { Aprofundamento do desenvolvimento e a identidade } \\
\text { profissional }\end{array}$ & 06 & 7,7 & 01 & 1,1 \\
\hline & Aprofundamento Teórico & 06 & 7,7 & 01 & 1,1 \\
\hline & Aproximação com a realidade & 15 & 19,2 & 14 & 16,1 \\
\hline & Integração entre as disciplinas & 9 & 11,5 & 04 & 4,6 \\
\hline & O exercício da prática profissional & 10 & 12,8 & 23 & 26,4 \\
\hline & Relevância para a iniciação científica & ---- & $\begin{array}{ll}---- \\
\end{array}$ & 02 & 2,3 \\
\hline & Não respondeu & 21 & 26,9 & 33 & 37,9 \\
\hline & & 78 & $100 \%$ & 87 & $100 \%$ \\
\hline
\end{tabular}

Fonte: Informações coletadas no questionário

Esse paradoxo entre reconhecer o practicum como elemento muito relevante e como aspecto que mais fez falta, indica, por um lado a tomada de consciência, por parte dos professores, da complexidade e da dinamicidade do contexto de atuação profissional docente, uma vez que ele se modifica neste intervalo entre o estar estagiário(a) e o estar professor(a) em um determinado contexto. Por outro lado, também indica uma necessidade potencial de tornar o practicum uma dimensão com certa centralidade durante o processo de formação, uma vez que ele se refere à oportunidade de experimentar aprendizagens (saber-fazer), de operar e desenvolver conhecimentos (saber), estabelecer relações interpessoais para o desenvolvimento profissional (saber ser, saber estar, saber conviver), favorecendo a interconexão entre contexto formativo e contexto produtivo (TEJADA; CARVALHO, 2013).

Deste ponto de vista, o Practicum, seja por meio da Prática Pedagógica ou do Estágio Supervisionado é o espaço e o tempo de encontros, de confrontos, de convergências, de reflexões, de análises, de problematizações e de sistematizações que ancoram a construção das 
aprendizagens indicadas anteriormente, potencializando a efetiva práxis no currículo de formação inicial de professores.

\section{Aspectos determinantes do curso para a inserção profissional}

A passagem de estudante para profissional docente não é tão simples. Trata-se de passar de uma fase de aprendizagens construídas em um espaço de formação, no caso a Universidade, para outra fase que também é de intensa aprendizagem do processo de ensinar em que vai, paulatinamente, definindo a atuação docente na busca de um maior equilíbrio pessoal e profissional.

Ainda no período de formação inicial, e quanto mais ele se aproxima do seu término, o vislumbre, ou não, com a atuação profissional se faz presente. Deste modo, a percepção do percurso profissional dos participantes deste estudo se dá a partir de elementos que começam a ser construídos ainda no período de formação inicial de professores, uma vez que a profissão professor é resultado de experiências que o profissional vivência durante toda a sua vida, cujas representações e concepções vão sendo elaboradas em um período longitudinal constituído em várias etapas de maneira dinâmica e relacional.

Uma dessas etapas é o próprio período de formação inicial. Ou seja, os processos vivenciados neste período em que se legitima, socialmente e oficialmente, a constituição de um determinado profissional, mediante a sua diplomação, neste caso o professor, que serão levados como referências para os primeiros anos/experiência da vida profissional.

Assim, questionados sobre os aspectos do curso de formação inicial considerados determinantes para a inserção profissional, os 46 egressos de cada instituição que exercem atividade profissional docente apresentam os seguintes aspectos, conforme organizados na tabela 07.

Tabela 07: Aspectos determinantes do curso para a inserção profissional

\begin{tabular}{l|c|c|c|c}
\hline \multirow{2}{*}{\multicolumn{1}{c|}{ Variáveis }} & \multicolumn{2}{c|}{ Egressos UB } & \multicolumn{2}{c}{ Egresso UP } \\
\cline { 2 - 5 } & $\mathrm{f}=$ & $\%$ & $\mathrm{f}=$ & $\%$ \\
\hline Qualidade do curso na universidade pública & 09 & 11,5 & 09 & 10,3 \\
\hline Conhecimento Teórico / Pedagógico & 12 & 15,4 & 11 & 12,5 \\
\hline Prática & 17 & 22 & 20 & 23 \\
\hline Dimensão Relacional & 08 & 10,2 & 06 & 6,9 \\
\hline & 46 & $59 \%$ & 46 & $52,9 \%$ \\
\hline
\end{tabular}

Fonte: Informações coletadas no questionário 
Em um primeiro aspecto destacado, $11,5 \%$ dos egressos da UB ( $f=09$ ) e $10,3 \%$ dos egressos da UP $(f=09)$ indicam que ter tido a formação em uma universidade pública, fez diferença no momento de inserção profissional, uma vez que essas universidades apresentam um quadro de profissionais qualificados, comprometidos com processos de pesquisa, com atividades de extensão e com a produção de conhecimento. Também, a própria estrutura universitária, estabelecida a partir do tripé ensino, pesquisa e extensão, favorece aos estudantes experiências integradas que resultam em uma mais valia na própria formação profissional.

No segundo aspecto, $15,4 \%$ dos egressos da UB ( $f=12$ ) e $12,5 \%$ dos egressos da UP ( $f=11)$ fazem referência à qualidade do currículo formativo, demarcando que o conhecimento teórico e pedagógico construídos nos cursos em questão foram fundamentais para a sustentação das opções que os professores precisam fazer no desenvolvimento de sua atividade profissional, nas situações emergentes do contexto escolar que demandam ações, muitas vezes imediatas.

No terceiro aspecto, $22 \%$ dos egressos da UB $(f=17)$ e $23 \%$ dos egressos da UP $(f=20)$ indicam a prática experienciada e realizada durante a formação como elemento fulcral para a inserção profissional, confirmando informações apresentadas anteriormente, quanto a relevância do practicum na formação inicial de professores. A experiência em programas de iniciação à docência, projetos interdisciplinares de investigação pedagógica, os estágios bem realizados e supervisionados, o contato com a realidade escolar, contribuíram para o desenvolvimento da consciência do papel formador da escola, de modo que, estar naquele contexto, enquanto profissional, após a conclusão da formação inicial é uma passagem com menos impactos e choques com a realidade.

Um quarto aspecto evidenciado pelos egressos diz respeito ao desenvolvimento pessoal, nomeadamente, desenvolvimento relacional, experienciados na formação inicial, que também se tornam determinantes no processo de indução profissional. $10,2 \%$ dos egressos da UB $(f=08)$ e 6,9\% dos egressos da UP ( $f=06$ ) reconhecem que tais elementos evidenciam a necessidade de a formação inicial de professores contemplar, em seu processo, diversas dimensões, que não só as acadêmicas, conforme apontam Alonso e Silva (2005, p.52-53) ao mencionar três áreas do perfil profissional - a saber: competências curriculares e pedagógico-didáticas; competências de investigação e reflexão; e, competências e atitudes pessoais e relacionais - que precisam ser consideradas na formação e que contribuem para o desenvolvimento profissional. 
Essas competências atitudinais e relacionais em que se destaca a capacidade de realizar trabalhos coletivos, desenvolvendo atitudes de respeito, de cooperação e de partilha, contribui para a compreensão da profissão professor em uma dimensão de classe e de conjunto que se sobrepõe a individualidade, tão bem sedimentada na história da profissional e que deve ser superada.

\section{Considerações finais}

Guardada as devidas especificidades de cada contexto, tanto de formação quanto de atuação profissional, o convite para que professores brasileiros e portugueses, egressos de duas universidades específicas que mantem um convênio de cooperação técnico-científico-cultural, estabelecessem um olhar retroativo para o processo de formação inicial, nos evidenciam possibilidades para um diálogo luso-brasileiro neste campo.

Ao estar na atividade profissional, vivenciando as exigências do contexto, percebemos que os professores conseguem elucidar elementos que se configuram, simultaneamente, em potencialidades quanto em limitações da formação inicial. Entretanto, é preciso considerar que, reconhecer tais limitações, não significa desconsiderar a formação inicial ou entendê-la como insuficiente, mas de compreender que o percurso profissional é um processo de construção configurado por tempos diferentes e por inúmeros intervenientes que são específicos do contexto de atividade profissional e que, por mais que a formação inicial se esforce, ela não conseguirá envolvê-los na sua totalidade.

Ao considerar o currículo de formação, seja em seus aspectos teóricos, metodológicos e práticos, é notável que a evidência recai sobre o practicum, enquanto um componente que, em grande medida, é considerado responsável pela formação profissional que deve possibilitar o desenvolvimento de habilidades e competências para uma determinada ação, que no caso do professor, é "ensinar".

A contradição no reconhecimento de que o practicum, ao mesmo tempo em que é fundamental, é insuficiente para dar respostas assertivas aos desafios profissionais, nos indica o quanto se faz necessário, mesmo no processo de formação inicial, desenvolver a consciência de que a atividade profissional docente não se faz em um percurso linear, onde sua constituição se 
efetiva por avanços crescentes de complexidades e por sobreposições de desafios também crescentes. Muito pelo contrário, a competência para ensinar não está construída, totalmente, no término da formação inicial, ela é uma aprendizagem que ocorre com a inserção profissional e que dependem exclusivamente do contexto da prática que, embora se faça presente no período da formação inicial, não se mostra suficiente, até porque os estudantes ainda se encontram neste período formacional em que a universidade acaba por assumir maior relevância.

Esta dimensão nos faz considerar a necessidade de pensar, por um lado, em um currículo de formação em rede que considere a articulação entre universidade e escola de educação básica, uma vez que a construção do conhecimento profissional se efetiva, já na formação inicial, em diferentes possibilidades experienciais nas quais os acadêmicos possam se inserir no sentido de consolidar o seu processo de aprendizagem em outros espaços, que não só as disciplinas e as salas de aula.

Por outro lado, reconhecer a potencialidade da formação continuada centrada na escola, comprometida com a melhoria da compreensão do fenômeno educativo, que é localizado em um determinado espaçotempo único, que é uma iniciativa que deve ser assumida, não no sentido de evidenciar deficiências (na própria formação), mas de se desenvolver na perspectiva da resolução de problemas que são reais do contexto de sala de aula que, nem sempre, são perceptíveis no momento da formação inicial em sua plenitude.

Deste modo, conclui-se que, refletir sobre a formação inicial, estando em atividade profissional, é, sem dúvida, um exercício que aponta elementos da formação inicial que devem ser considerados pelas instituições em questão, sobretudo no que diz respeito ao desenvolvimento curricular na perspectiva de compreender e reafirmar o contexto de atividade profissional enquanto parceiro no processo de formação. De igual modo, que convida os contextos de atividade profissional cuidarem com mais afinco do desenvolvimento de seus profissionais, investindo em uma formação continuada capaz de responder às exigências do complexo processo de ensinar e de aprender. 


\section{Referências}

ALARCÃO, I. Reflexão crítica sobre o pensamento de D. Schön e os programas de formação de professores. In: ALARCÃO, I. (org.). Formação reflexiva de professores: estratégias de supervisão. Portugal: Porto Editora, p.11-39, 1996.

ALONSO, L. Inovação curricular, formação de professores e melhoria da escola: uma abordagem reflexiva e reconstrutiva sobre a prática da inovação/formação. 1998. 610f. Tese (Doutoramento em Estudo da Criança) - Instituto de Estudos da Criança, Universidade do Minho, Braga, 1998.

ALONSO, L.; SILVA, C. Questões críticas acerca da construção de um currículo formativo integrado. In: ALONSO, L.; ROLDÃO, M. C. Ser professor do 1o ciclo: construindo a profissão. Coimbra: Almedina, 2005, p.43-63.

CUNHA, M. I. C. Inovações pedagógicas: o desafio da reconfiguração de saberes na docência universitária. São Paulo: Universidade de São Paulo, 2008.

FARIAS, I. M. S. et al. Didática e docência: aprendendo a profissão. Brasília: Liber, 2009.

FLORES, M. A. A indução no ensino: desafios e constrangimentos. Lisboa: Instituto de Inovação Educacional, 2000.

FORMOSINHO, J. A formação prática dos professores: da prática docente na instituição de formação à prática pedagógica nas escolas. In: FORMOSINHO, J. (Org.). Formação de professores: aprendizagem profissional e acção docente. Porto: Porto, 2009. p.93-115.

GARCIA, C. M. Formação de professores: para uma mudança educativa. Porto: Porto Editora, 1999.

GASPARINI, S. M.; BARRETO, S. M.; ASSUNÇÃO, A. O professor, as condições de trabalho e os efeitos sobre sua saúde. Educação e Pesquisa, São Paulo, v.31, n.2, p.189-199, maio/ago. 2005.

HUBERMAN, M. O ciclo de vida profissional dos professores. In: NÓVOA, A. (org). Vidas de professores. 2. ed. Porto: Porto Editora, 2013. p.31-62.

LIBÂNEO, J. C. Pedagogia e pedagogos, para quê? 9. ed. São Paulo: Cortez, 2007.

PENNA, M. G. O. Professor iniciante: considerações sobre aspectos do habitus familiar e a socialização na docência. In: GIOVANNI, L. M; MARIN, A. J. Professores iniciantes: diferentes necessidades em diferentes contextos. Araraquara, SP: Junqueira \& Marin, 2014. p.45-60.

ROLDÃO, M. C. A formação como projecto: do plano-mosaico ao currículo como projecto de formação. In: CAMPOS, B. P. (org.). Formação profissional de professores no ensino superior. 
Porto: Porto Editora, 2001, p.6-20.

ROLDÃO, M. C. Função docente: natureza e construção do conhecimento profissional. Revista Brasileira de Educação, v.12, n.34, p.94-181, jan./abr. 2007.

NÓVOA. A. Devolver a formação dos professores aos professores. Cadernos de Pesquisa em Educação, Vitória, ano 9, v.18, n.35, p.11-22, jan.-jun. 2012.

SERRALHEIRO, J. P. Os processos de Bolonha e a formação dos educadores e professores portugueses. Porto: Profedições, 2005.

SILVA, C.; FELÍCIO, H. M. S. Entre o conhecimento escolar, os processos de ensino e aprendizagem e os saberes docentes: uma experiência luso-brasileira na formação de professores. Revista Eletrônica Pesquiseduca, v.9, n.18, p.357-379, 2017.

TARDIF, M. Saberes docentes e formação de professores. Petrópolis: Vozes, 2002.

TARDIF, M.; RAYMOND, D. Saberes, tempos e aprendizagem do trabalho no magistério. Educação \& Sociedade, ano XXI, n.73, p.209-244, dez. 2000.

TEJADA, J. F.; CARVALHO, M. L. El prácticum en la formación inicial de maestros: percepciones de los tutores de universidad de educación infantil y primaria. In: SYMPOSIUM INTERNACIONAL SOBRE EL PRACTICUM Y LAS PRÁCTICAS EM EMPRESAS EM LA FORMACIÓN UNIVERSITARIA, 12., 2013, Santiago de Compostela. Actas [...]. Santiago de Compostela: Andavira, 2013. p.1583-1596.

ZEICHNER, K. M. Novos caminhos para o practicum: uma perspectiva para os anos 90 . In: NÓVOA, A. (org.). Os professores e sua formação. Lisboa: Publicações Dom Quixote / Instituto de Inovação Educacional, 1992. p.115-138.

Recebido em abril 2021.

Aprovado em junho 2021. 